\title{
Inhibitors of Bacterial Topoisomerases: Mechanisms of Action and Resistance and Clinical Aspects ${ }^{1}$
}

\author{
Peter Heisig \\ Pharmazeutische Biologie Universität Hamburg, Hamburg, Germany \\ Received: May 26, 2000; Accepted: August 19, 2000
}

\begin{abstract}
The quinolone class of inhibitors of bacterial type II topoisomerases has gained major clinical importance during the last years due to improvements in both pharmacokinetic and pharmacodynamic properties. These include favorable bioavailability allowing oral administration, good tolerability, high tissue concentrations as well as superior bactericidal activity against a broad spectrum of clinically relevant pathogens, like enterobacteria, Pseudomonas aeruginosa, Staphylococcus aureus, and Streptococcus pneumoniae. In addition, no enzymatic mechanism of drug inactivation exists in bacteria and no indications for transfer of clinically relevant resistance exist. Nevertheless, resistance is being increasingly reported, even for naturally highly susceptible species like Escherichia coli. The underlying mechanisms of resistance include alterations in both bacterial targets, DNA gyrase and topoisomerase IV, often combined with mutations affecting drug accumulation, e.g., by increased drug efflux, reduced drug influx, or both. Investigations aiming at understanding the molecular mechanisms of quinolone action and resistance in more detail should provide a basis for a rational design of more potent derivatives. In addition, a prudent use of these highly valuable "magic bullets" is necessary to preserve their potential for the future.
\end{abstract}

Key words: Bacterial topoisomerase, fluoroquinolone, bacteria and antibiotic resistance.

\section{Introduction}

According to the World Health Report on Infectious Diseases 2000 overcoming antibiotic resistance is the major issue of the WHO for the next millenium. Currently, antibiotics provide the main basis for a causative therapy of bacterial infections. However, the high genetic variability of bacteria enables them to rapidly evade the action of antibiotics by developing antibiotic resistance. Thus, there has been a continuing search for new, more potent antibiotics.

During the last decades a limited number of well established classes of antibiotics, e.g., $\beta$-lactams, macrolides or quinolones, have been investigated extensively to identify the

Planta Med 67 (2001) 3-12

(c) Georg Thieme Verlag Stuttgart · New York ISSN: 0032-0943 mechanism of action and the molecular structure of the target site. Based upon this knowledge, new antibiotics were designed by chemical modification of approved prototype compounds. However, this led to a limitation of therapeutic options for those bacteria which have already developed high resistance to these prototypes.

In contrast, the novel genomics approach uses DNA sequence data bases to identify novel lethal targets. However, sophisticated systems for high-throughput screening of chemical and biological molecule libraries are needed in order to identify lead compounds, which subsequently require additional research capacities for elucidating the underlying mechanism of action (1).

Starting with a well characterized target structure to screen for alternate, chemically unrelated inhibitors seems to be another promising approach. Thus, bacterial type II topoisomerases can be considered as targets not only for known but also for potential novel antibiotics.

\section{DNA Toposiomerases}

Topoisomerases play an essential role for the control of the three-dimensional DNA structure in all cells (eubacteria, eukaryote, archaea). According to their mechanism of action topoisomerases are classified as type I or type II enzymes [for a recent review see (2)].

The first topoisomerase detected was the bacterial type I enzyme, topoisomerase I (3), which in cooperation with DNA gyrase, a bacterial type II enzyme, enzymatically controls the maintenance of the DNA supercoiling degree (4). Among all topoisomerases DNA gyrase is unique by its ability to introduce so-called negative supercoils into covalently closed circular (ccc) double stranded DNA in the relaxed state (Fig. 1).

DNA gyrase holoenzyme consists of two pairs of subunits, GyrA and $\mathrm{GyrB}$, the products of the corresponding genes gyrA and gyr $B$, respectively, and forms a tetrameric structure $\left(A_{2} B_{2}\right)$ (Fig. 2). Both subunits contain functional domains involved in interactions with DNA, with ATP (ATP-binding motif in GyrB), and between subunits $A$ and $B$ [for a review see ref. (5)] Fig. 2).

\footnotetext{
${ }^{1}$ Experimental work was performed at the Department of Pharmaceutical Microbiology at the University of Bonn
} 


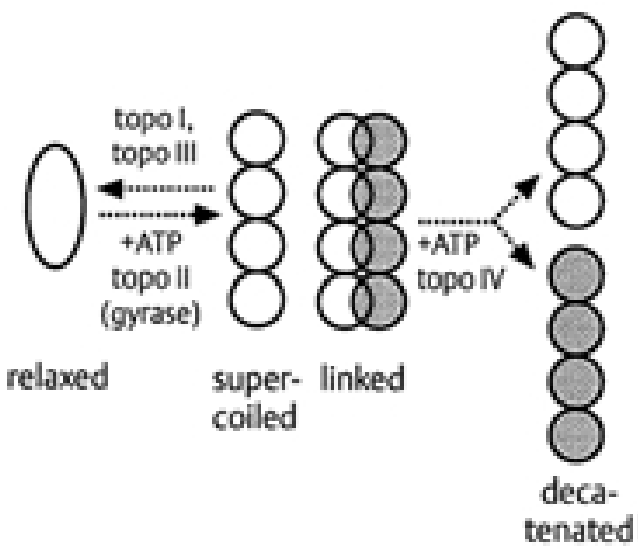

Fig. 1 Biological functions of bacterial topoisomerases. In the relaxed state of a covalently closed circular DNA in the B conformation the helical axis is planar. Every 10.4 base pairs (bp) one DNA strand its wound around the other forming one helical turn and, simultaneously, the two strands are topologically linked like links of a chain. Thus, in the relaxed state the number of links equals the number of turns and the helical axis is planar. At the expense of ATP hydrolysis topoisomerase II (DNA gyrase) converts a ccc DNA from the relaxed to the supercoiled state. This poses torsional stress to the DNA molecule, which is relieved by writhing the helical axis into the space (supercoiled form). In one reaction cycle (Fig. 2) DNA gyrase reduces the number of topological links between the DNA strands in steps of two (type II topoisomerase) while maintaining the number of helical turns constant according to the B conformation. Thus, by definition, two negative supercoils are introduced, i.e., the DNA molcule is "underwound". (Increasing the number of topological links yields positive supercoils). Negatively supercoiled DNA has a higher content of energy, which is exploited to facilitate local unwinding of, e.g., promoter regions and to drive polymerization reactions along the DNA strands (DNA replication, transcription). To maintain a moderate level of negative supercoiling topoisomerase I and, under certain circumstances (i.e., recombinational repair events), topoisomerase III catalyze relaxation of negatively supercoiled DNA. Topoisomerase IV is another type II toposiomerase capable of separating daughter chromosomes at the end of a replication cycle before cell division occurs. Topo IV reaction also consumes ATP (5).

The current model explaining the molecular mechanism of action of type II topoisomerases is based upon biochemical and genetic investigations of DNA gyrase from $E$. coli and crystallographic analysis of a homologous type II topoisomerase from Saccharomyces cerevisiae (6), (7). This model postulates a multi-step mechanism schematically outlined in Fig. 2.

Recently, another bacterial type II topoisomerase, topoisomerase IV (topo IV), has been identified in E. coli (8). Both enzymes - gyrase and topo IV - share several structural and functional features. Based upon protein sequence homology to DNA gyrase, analogous domains (e.g., ATP-binding) are assigned to subunits $\mathrm{A}$ (ParC) and B (ParE) of topo IV. In contrast to DNA gyrase, topo IV catalyzes the separation (decatenation) of two double-stranded ccc DNA molecules intertwined like links of a chain (Fig. 1). This is a prerequisite for the termination of the DNA replication and the subsequent cell division (9).

While the gyrase-mediated reaction involves intramolecular strand passage (the T-segment belongs to the same DNA molecule as the G-segment, Fig. 2) topo IV favors an intermolecular strand transfer (T-segment is part of a second ccc

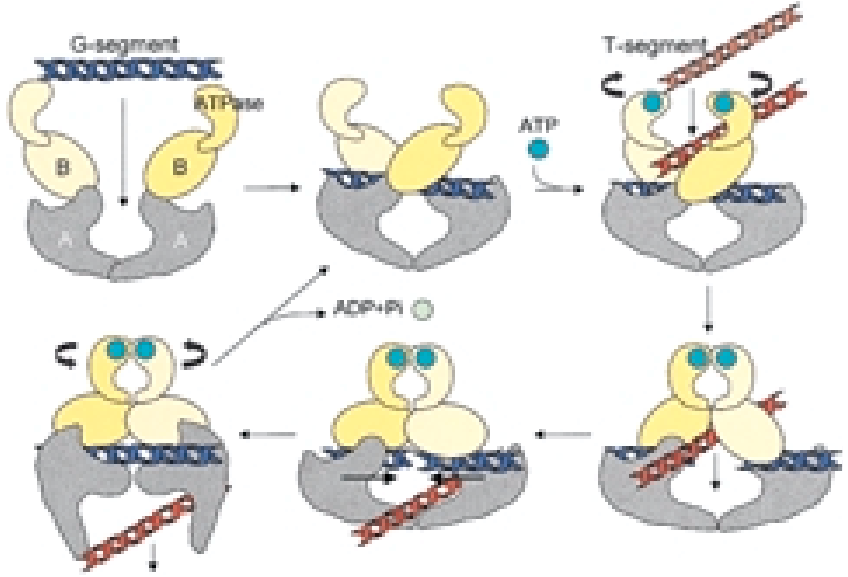

Fig. 2 Mechanism of action of DNA gyrase. DNA gyrase binds a small (approx. $120 \mathrm{bp}$ ) DNA segment (G-segment), presumably by wrapping it around the holoenzyme. After binding of ATP the B-subunits dimerize thereby trapping a distant DNA segment (T-segment) within the enzyme. A 4 bp staggered double-strand break is introduced into the G-segment. Transiently, the resulting free 5 '-phosphate ends of both DNA strands are covalently attached to conserved tyrosine residues $(Y-122)$ of the $A$ subunits via phosphate ester bonds. This results in the formation of an enzyme-operated DNA gate. The T-segment is passed through this DNA gate and then released. The DNA break is resealed and the initial conformation of the enzyme is restored at the cost of ATP hydrolysis. [Modified according to (7)].

DNA molecule). The ubiquitous distribution among all bacteria and the uniqueness of the supercoiling reaction makes DNA gyrase an "ideal" lethal target for broad-spectrum antibiotics.

\section{Inhibitors of Bacterial Type II Topoisomerases}

Several inhibitors of DNA gyrase and/or topo IV have been identified so far. These include (i) the GyrA-targeting $3.2 \mathrm{kD}$ glycine-rich peptide MccB17, which has been isolated from enterobacteria carrying the corresponding biosynthetic gene cluster on a plasmid (10), (ii) the cyclic peptide cyclothialidine isolated from Streptomyces and its derivative GR122222X (Fig. 3), which interfere with binding of ATP to the GyrB subunit (11), (iii) cinodine (Fig. 3), a glycocinnamoylspermidine antibiotic, which is produced by Nocardia species (12) and targets gyrase as indicated by studies with cinodine-resistant mutants of $E$. coli (13), (iv) clerocidin (Fig. 3), a terpenoid antibiotic from Fusidium viridae, which beside its cytotoxic activity on mammalian topoisomerase II also acts on the DNA gyrase A-subunit (14), (15) (Fig. 3).

Since topo IV has only recently been identified as a second quinolone target, most of these drugs have not yet been investigated for their activity on this enzyme. There is one report on the inhibitory activity of the glycosylated flavonoids rutin and isoquercitrin preferrentially on topo IV (16).

None of these compounds has yet been developed for clinical use as antimicrobials, probably due to high toxicity (activity on eukaryotic targets), unfavourable pharmacokinetic properties (high molecular weight causing low membrane permeability) or risk of cross-resistance (overlapping binding sites). 


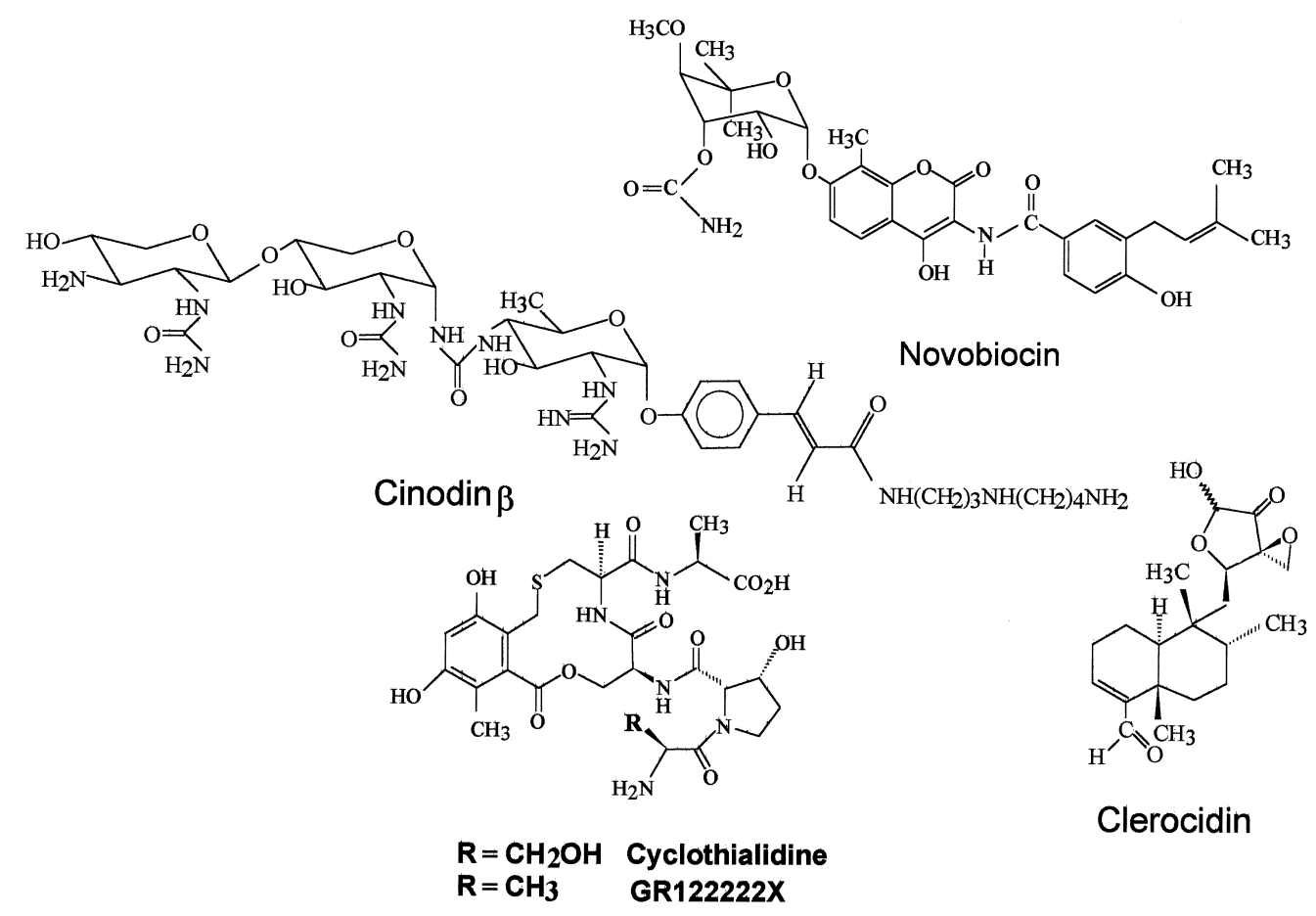

Fig. 3 Inhibitors of DNA gyrase.
In contrast, two classes of inhibitors of bacterial type II topoisomerases, coumarin antibiotics and quinolones, are successfully used for treatment of infections due to Gram-positive and Gram-negative pathogens.

The coumarin antibiotics novobiocin (Fig. 3), chlorobiocin, and coumermycin $A_{1}$, which are naturally produced by Streptomyces species, interact with the $\mathrm{N}$-terminal amino acids of the GyrB subunit thereby stabilizing an enzyme conformation of low affinity for ATP (17), (18), (19). Due to their high molec- ular masses, coumarin antibiotics do not sufficiently penetrate the outer membrane of most Gram-negative bacteria (20). Thus, they are of minor clinical importance and are rarely used for the treatment of infections caused by some Grampositive pathogens.

Quinolones are synthetic compounds first described in 1962 by Lesher and coworkers. Nalidixic acid (Fig. 4), the prototype of the quinolone class of antimicrobials, actually is an aza-derivative (1,8-naphthyridine) of 4-quinolone-3-carboxylic acid.<smiles>CCn1cc(C(=O)O)c(O)c2c3ccc(C)nc3n1-2</smiles>

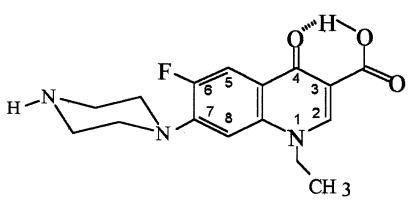<smiles></smiles>

Sparfloxacin<smiles></smiles>

Pefloxacin

Fig. 4 Quinolone antibacterials.

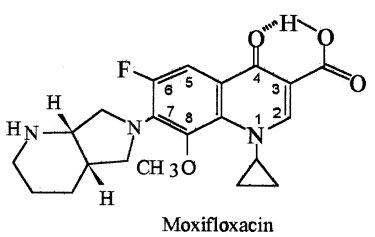

Moxifloxacin

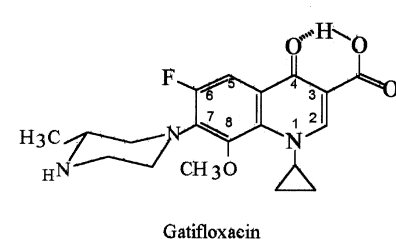

Gatifloxacin

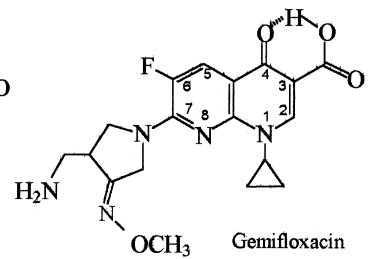

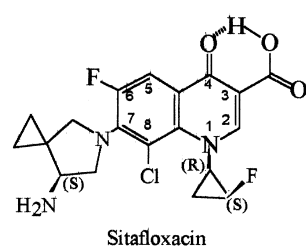


Table 1 Quinolone susceptibilities of various bacterial pathogens.

\begin{tabular}{|c|c|c|c|c|}
\hline Species & \multicolumn{4}{|c|}{$\mathrm{MIC}_{90}[\mu \mathrm{g} / \mathrm{ml}]$} \\
\hline E. coli & 4 & 0.125 & 0.015 & 0.008 \\
\hline P. aeruginosa & $>128$ & 4 & 0.25 & 0.125 \\
\hline A. baumanii & 8 & 8 & 0.5 & 0.125 \\
\hline H. influenzae & 1 & 0.06 & 0.015 & 0.004 \\
\hline H. pylori & n.d. ${ }^{*}$ & n.d. & 0.5 & 0.125 \\
\hline M. pneumoniae & n.d. & 16 & 0.5 & 0.03 \\
\hline B. fragilis & 512 & 128 & 8 & 2 \\
\hline S. aureus & 64 & 2 & 0. & 0.06 \\
\hline S. pneumoniae & $>128$ & 16 & 2 & 0.5 \\
\hline E. faecalis & $>128$ & 8 & 2 & 1 \\
\hline M. tuberculosis & 128 & 2 & 1 & 0.25 \\
\hline
\end{tabular}

*n.d.: not data.

It is derived from a by-product of the chloroquine synthesis (21). Nalidixic acid shows clinically relevant drug concentrations only in urine and has a narrow range of activity against some Gram-negative enterobacteria, restricting its clinical use to the treatment of enterobacterial urinary tract infections. Attempts to broaden its antibacterial spectrum of activity led to norfloxacin, a 4-quinolone-3-carboxylic acid carrying a 6-fluoro and a 7-piperazinyl substituent (Fig. 4, Table 1) (22). In addition to an at least 100-fold increase in the antibacterial activity against Gram-negative bacteria, norfloxacin has also a weak, though significant activity against Staphylococcus aureus (23). Heteroyclic substituents at the C7-position, e.g., gemifloxacin have improved the activity against Gram-positives (Fig. 4, Table 1). another significant improvement came from variations at positions $\mathrm{C} 1$ and $\mathrm{C} 8$ leading to sitafloxacin, moxifloxacin or gatifloxacin (Fig. 4).

According to their clinical indication and application, Naber et al. recently suggested to divide fluoroquinolones into four classes (Table 2) (24). While ciprofloxacin is the most active fluoroquinolone against Gram-negative pathogens including Pseudomonas aeruginosa, the new derivatives, e.g., those belonging to classes III and IV are also active against various Gram-positives, like S. aureus, S. pneumoniae (25), (26), (27), (28), (29), (30), as well as Mycobacterium tuberculosis (31), (32), (33) (Table 1). Thus, the new fluoroquinolones have a high efficacy in the treatment of respiratory tract infections covering not only the common pathogens S. pneumoniae, $\mathrm{He}$ mophilus influenzae, and Moraxella catarrhalis, but also the uncommon Chlamydia pneumoniae, Legionella pneumophila, and Mycoplasma pneumoniae (34).

\section{Mechanism of Action of 4-Quinolones}

Quinolone antibacterials display bactericidal activity against dividing cells (Fig. 5a) resulting in a rapid decrease of the viable cell count by several orders of magnitude (35). This is due to the inhibition of the replicative DNA synthesis rather than protein or RNA synthesis (Fig. 5 b) (36). Evidence for DNA gy-
Table 2 Classification of fluoroquinolones (24).

\begin{tabular}{lll}
\hline I & Oral application, exclusively & Norfloxacin \\
used for urinary tract infections (UTI) & Pefloxacin \\
II & Systemic application, wide indication & (Enoxacin, oral) \\
(UTI, respiratory tract infections (RTI), & Fleroxacin \\
bone and soft tissue infectiosn, sepsis) & Ofloxacin \\
& Ciprofloxacin \\
& Increased activity against Gram- & Levofloxacin \\
III & Sparfloxacin \\
& positive and "atypical" (mycobacteria) & (Grepafloxacin) \\
RTI, bone infections & Gatifloxacin* \\
IV Like III + anaerobes & Gemifloxacin* \\
& RTI & (Trovafloxacin) \\
& Moxifloxacin \\
& (Clinafloxacin)*
\end{tabular}

rase as the target of quinolones came from Gellert et al., who found the inhibitory concentration of oxolinic acid for DNA gyrase isolated from a quinolone-susceptible strain to be much lower than that of its quinolone-resistant derivative carrying a mutation in the structural gene gyrA, formerly called nalA (Fig. 5c) (37).

Quinolones act by formation of a stable ternary complex consisting of (i) DNA, covalently attached to (ii) DNA gyrase A subunits of the $\mathrm{A}_{2} \mathrm{~B}_{2}$ tetramer, and (iii) quinolones thereby preventing the religation step. As a consequence the progress of DNA- and RNA-polymerases along the DNA is blocked. A stop of DNA replication induces the SOS response (38), which triggers the synthesis of new proteins resulting in an arrest of cell division, cessation of the respiratory chain and finally in cell death by an as yet incompletely understood mechanism (39).

\section{Mechanisms of Bacterial Resistance to Quinolones}

In general, two basic genetic events can lead to antibiotic resistance - acquisition of additional DNA coding for a resist- 
ance determinant and alteration of existing genetic information, e.g., by a mutation. In case of the quinolones, transfer of clinically relevant resistance determinants has not yet been reported.

First experiments to select single-step mutants of E. coli with reduced susceptibility to nalidixic acid yielded two types of mutants (40): NalA-type mutants show a significant increase of the minimal inhibitory concentration (MIC) of all quinolones, while nalB-type mutants show only a moderate increase in the MICs of quinolones, but a reduction in the quino-

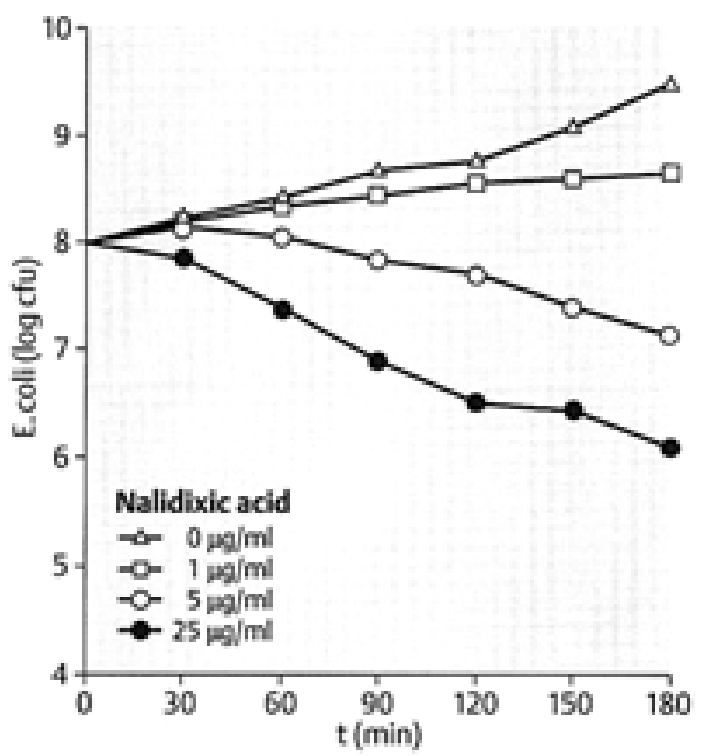

Fig. 5 a Bactericidal activity of quinolones. Addition of nalidixic acid in different concentrations $(1,5$, and $25 \mu \mathrm{g} / \mathrm{ml}$ ) to exponentially growing cells of a quinolone-susceptible strain of E. coli resulted in a concentration-dependent reduction in the viable cell count during 180 min. These data indicate the bactericidal mechanism of quinolones. [Data according to results of (35)].
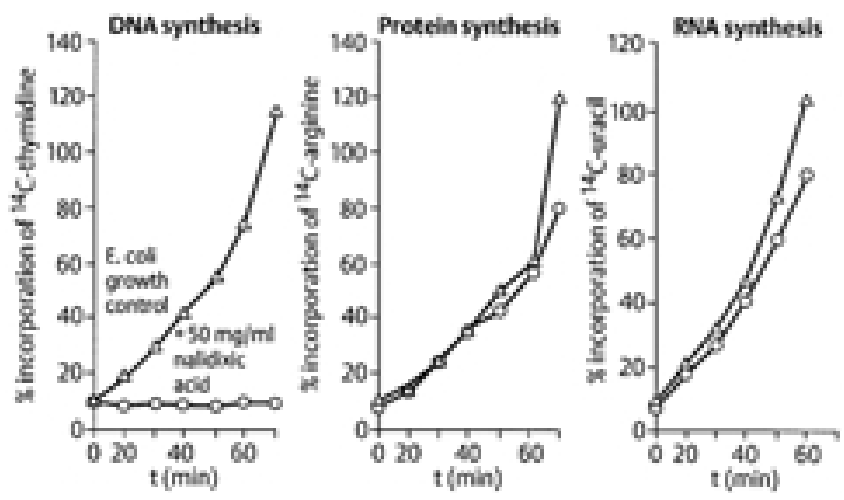

Fig. 5b Mechanism of action of quinolones - inhibition of DNA synthesis. The addition of nalidixic acid (final concentration $50 \mu \mathrm{g} /$ $\mathrm{ml}, \mathrm{O}-\mathrm{O})$ did not affect the incorporation of radio-labelled precursors of protein synthesis $\left({ }^{14} \mathrm{C}\right.$-arginine, center) and of RNA synthesis $\left({ }^{14} \mathrm{C}\right.$-uracil, right) by cells of $E$. coli compared to an untreated control $(\triangle-\triangle)$ ). In contrast, the incorporation of ${ }^{14} \mathrm{C}$-thymidine (left) is abolished immediately after the addition of nalidixic acid indicating that quinolones are inhibitors of DNA replication. [Data according to results of (36)].

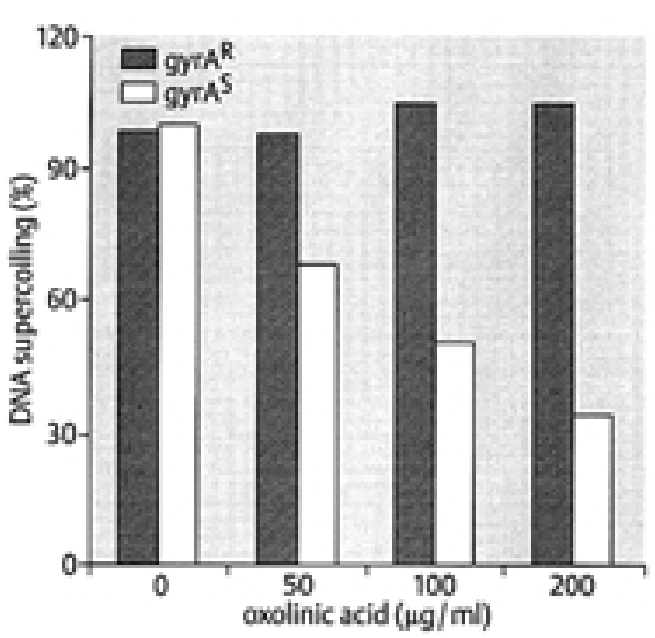

Fig. 5c Molecular mechanism of action of quinolones - inhibition of DNA gyrase. The enzymatic supercoiling activity of DNA gyrase ( $g y r A^{S}$, white columns) isolated from a quinolone susceptible isolate of $E$. coli is inhibited by the addition of oxolinic acid in a concentration dependent manner. No effect is observed with DNA gyrase $\left(g y r A^{R}\right.$, shaded columns) isolated from an E. coli strain carrying a single mutation in the gene gyrA (formerly nalA) coding for a quinolone-resistant A subunit. [Data according to results of (37)].

lone concentration required for inhibiting DNA replication after EDTA treatment, indicating that nalB is a transport mutant. No bacterial mechanism capable of inactivating quinolones has been reported so far, although some wood-rotting fungi have been demonstrated to significantly contribute to the degradation of fluoroquinolones in the environment (41).

In contrast to the older, unfluorinated quinolones growth of both types of mutants, nalA and nalB, can be inhibited by new fluorinated quinolones at clinically relevant concentrations. As a consequence, using even high inocula of about $10^{12}$ cells it is impossible to select single-step mutants of E.coli with clinically relevant resistance to fluoroquinolones (42).

The lack of resistance gene transfer and enzymatic drug inactivation together with the high activity of fluoroquinolones against single-step mutants of naturally quinolone-susceptible bacteria, like E. coli, led some investigators to deny the ability of these bacteria to develop clinically relevant resistance towards fluoroquinolones.

Obviously, this optimistic point of view underestimated the high genetic variability of bacteria: During the last decade an increase in the prevalence of fluoroquinolone resistant isolates of $E$. coli from less than $0.5 \%$ to about $10 \%$ has occurred (43). Such highly resistant clinical isolates show increases in the MICs of, e.g., ciprofloxacin from $0.015 \mu \mathrm{g} / \mathrm{ml}$ for a susceptible isolate to $64 \mu \mathrm{g} / \mathrm{ml}$ and higher for resistant isolates (44), (45), (46), (47).

\section{Target-Mediated Resistance Mechanisms in Gram-Negatives}

To elucidate the molecular basis for high-level fluoroquinolone resistance, sequential mutants of a wild-type quinolonesusceptible isolate (WT) have been selected in vitro. Three se- 
Table 3 Impact of GyrA double mutation S83L+D87G on ciprofloxacin (cip) susceptibility of isolated enzyme ${ }^{\text {(gyrase) }}$ and whole cells ${ }^{(w c)}$.

\begin{tabular}{llcl}
\hline Strain & $\begin{array}{l}\text { GyrA- } \\
\text { mutation }\end{array}$ & $\begin{array}{l}\mathrm{IC}_{90} \text { gyrase) } \\
\text { cip }[\mu \mathrm{g} / \mathrm{ml}]\end{array}$ & $\begin{array}{l}\mathrm{MIC}(\mathrm{wc}) \\
\mathrm{cip}[\cdot \mathrm{g} / \mathrm{ml}]\end{array}$ \\
\hline WT & - & 1 & 0.015 \\
$\mathrm{M} \mathrm{I}$ & S83L & 10 & 0.5 \\
$\mathrm{M} \mathrm{I}^{*}$ & D87G & 10 & 0.25 \\
M III & S83L+D87G & $>2000$ & 64 (selected in vitro) \\
WT-3 & S83L+D87G & $>2000$ & 1 (mutagenized) \\
321 & S83L+D87G & $>2000$ & 64 (clinical isolate) \\
\hline
\end{tabular}

* Obtained by in-vitro mutagenesis.

lection steps yielding mutants MI, MII, and MIII were necessary to obtain high-level resistance (MIII with MIC of ciprofloxacin of $64 \mu \mathrm{g} / \mathrm{ml}$ ) (48). Results of a genetic dominance test (49), which is based upon the dominance of a - plasmid-coded - quinolone susceptible over the - chromosomally encoded - resistant allele of gyrA (49) or gyrB (50) indicated the involvement of gyrA, but not gyrB mutations (48), (51). In addition, mutant MII carries an nalB-like mutation displaying a multiple antibiotic resistance (mar) phenotype (52) that affects susceptibility not only to quinolones - as indicated by a reduction in the accumulation of ciprofloxacin by about $70 \%$ - but also to unrelated drugs, like chloramphenicol (53).

Determining for WT and its derivatives the DNA sequence of the so-called "quinolone resistance-determining region" (QRDR) of gyrA, where all known single step mutations associated with quinolone resistance map (54), revealed a serine83 to leucine (S83L) mutation in mutant $\mathrm{MI}$ and, in addition, an aspartate-87 to glycine (D87G) mutation in mutant MIII (55). DNA supercoiling activity of DNA gyrase isolated from mutant MIII is as refractory to ciprofloxacin $\left(\mathrm{IC}_{90}>1,500 \mu \mathrm{g} /\right.$ $\mathrm{ml}$ ) as that of DNA gyrase reconstituted from a wild type GyrB subunit and a genetically engineered GyrA subunit containing solely the double mutation S83L+D87G (Table 3). Expanding the DNA sequence analyses to clinical isolates with high-level fluoroquinolone resistance revealed that it is associated with a gyrA double mutation primarily affecting codons for serine83 and aspartate-87 (53). In order to investigate if this double mutation is sufficient for the expression of high-level fluoroquinolone resistance, the susceptibilities to ciprofloxacin were determined for mutant MIII selected in vitro and mutant WT-3 which was obtained by in vitro mutagenesis. WT-3 contains only the gyrA double mutation S83L+D87G in the genetic background of WT. Mutant WT-3 was as susceptible as the single step mutant MI (Table 3), indicating the presence of an additional, yet unidentified mutation in MIII. Data of Hoshino et al. (56) demonstrating that fluoroquinolones inhibit in vitro the activity of topo IV at concentrations several fold higher than those required for inhibition of DNA gyrase, supported the idea that topo IV is an additional target of fluoroquinolones in E. coli.

This hypothesis was challenged by determining the DNA sequence of a fragment from parC containing the region homologous to the QRDR of gyrA for the susceptible parent strain WT and its derivatives MI, MII, and MIII. Compared to WT no alteration was found for MI and MII, however, mutant MIII did carry a mutation resulting in a serine- 80 to isoleucine change. Serine- 80 of ParC is homologous to serine- 83 for GyrA (Fig. 6).

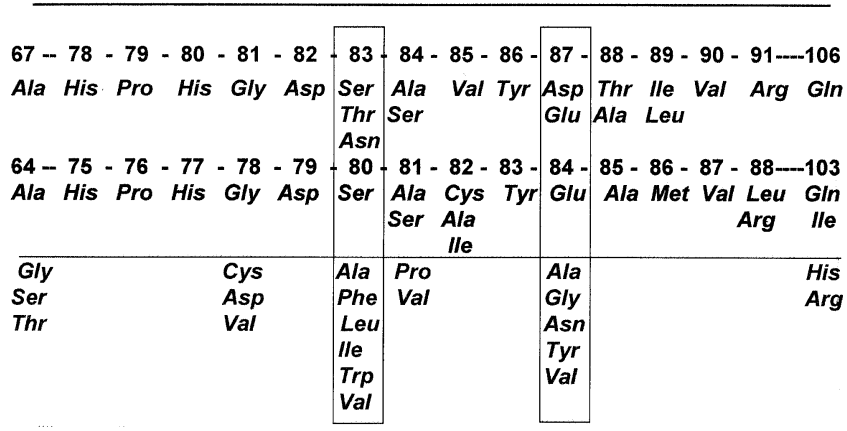

Fig. 6 Conserved amino acid sequences in GyrA and ParC of various Gram-negative bacteria and quinolone resistance mutations. According to the respective proteins from E.coli amino acids of the quinolone resistance-determining region [QRDR, (54)] of subunit $A$ of DNA gyrase (GyrA, top) and the homologous region of subunit A of topoisomerase IV (ParC, bottom) were numbered. Naturally variant amino acids of the respective genes detected in quinolonesusceptible strains of several Gram-negative species are given below the respective QRDR. Mutations associated with quinolone resistance in various Gram-negative isolates in subunits $A$ of both target topoisomerases are shown under below the line the respective amino acid positions (44), (45), (46), (47), (53), (60), (92), (93), (94).

Subsequent DNA sequencing of clinical isolates with high-level fluoroquinolone resistance revealed the presence of at least one mutation within the QRDR-like region of parC. All amino acids in ParC associated with quinolone resistance were homologous to those in GyrA (Fig. 6). Moreover, transfering a plasmid-coded quinolone-susceptible allele of parC obtained from strain WT into parC mutant strains (e.g., MIII) resulted in a reduction of the fluoroquinolone resistance to the level of a single gyrA mutant, but not to that of WT. This dominance effect was not observed if the parC gene obtained from mutant MIII was transferred (44).

These results indicating the requirement of a combiantion of mutations affecting both targets of quinolones, topo IV and DNA gyrase, are required for high-level resistance, do not only apply to E. coli (57), (58), (59), but also to other Gram-negative pathogens (60). Strains carrying a combination of three target mutations are resistant even to new derivatives like clinafloxacin, sitafloxacin showing highest antibacterial activity (61).

\section{Target-Mediated Resistance Mechanisms in Gram-Positives}

Ciprofloxacin and ofloxacin carrying modified N1-substituents were the first fluoroquinolones to be licensed for a broad indication including infections of the bone, the skin, and the soft tissue, which can be caused by $S$. aureus, a Gram-positive pathogen. However, the antibacterial activities of these fluoroquinolones against Gram-positives are weaker than against most Gram-negatives (Table $\mathbf{1}$ ). Thus, clinically resistant mutants of $S$. aureus can be obtained not only in a single step in vitro but also frequently from patients receiving fluoroquinolone therapy. Molecular genetic analysis of the underlying mechanism of resistance in S. aureus revealed that topo IV is the primary, more sensitive target, while DNA gyrase is secondary (62). One approach to improve the activity against Gram-positives was the chemical modification of the C8 position: Introducing a $-\mathrm{F}, \mathrm{a}-\mathrm{Cl}$, or a $-\mathrm{OCH}_{3}$ substituent yielded 
fluoroquinolones, like sparfloxacin, sitafloxacin, and moxifloxacin (Fig. 4) with enhanced activities against Gram-positives and several mycobacterial species, while retaining most of the activities against Gram-negatives (Table 1). However, a halogen substitutent is associated with phototoxicity limiting the use of, e.g., sparfloxacin and clinafloxacin (63). In contrast, no such side effects have been reported for moxifloxacin with a $-\mathrm{OCH}_{3}$ substitution.

In vitro data indicate that topo IV is the primary target of fluoroquinolones in Enterococcus faecalis (64), (65) and S. pneumoniae, too (66), although for S. pneumoniae the target preference seems to depend on the structure of the fluoroquinolone (67).

\section{Resistance due to Altered Drug Transport}

Accumulation of fluoroquinolones in the cytoplasm at relevant concentrations is due to both the chelating activity of the 4-oxo-3-carboxylic acid moiety, which destabilizes the lipopolysaccharide layer of the outer membrane (68), and the zwitterionic character of these drugs, allowing them to pass the cytoplasmic membrane by exploiting the proton gradient (Fig. 4) (69).

Drug accumulation in a Gram-negative bacterial cell can be reduced by two different mechanisms: (i) reduction of the drug influx into the cell through the outer membrane, the major barrier for hydrophilic molecules, and (ii) increase in drug efflux out of the cell by energy-driven transmembrane export (Fig. 7) (70).

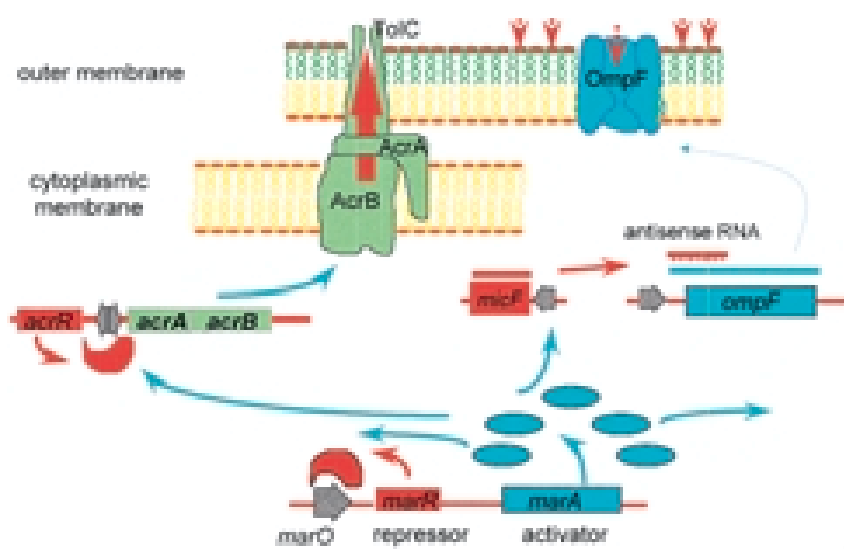

Fig. 7 Multiple antibiotic resistance in E. coli. The mar operon contains a transcriptional unit of three genes marR, marA, and marB, which are under negative control of the MarR repressor (95). Environmental stimuli, like salicylic acid or bile salts as well as mutations inactivating repressor activity (86) result in constitutive overexpression of MarA. This, in turn, activates several unrelated genes including that encoding the micF antisense RNA complementary to the 5 '-end of the ompF mRNA and those encoding the three-component efflux pump AcrAB-TolC capable of extruding antibiotics like quinolones or chloramphenicol (96). Thus, the intracellular concentration of quinolones is significantly reduced by simultaneously decreasing drug influx (via OmpF) and increasing drug efflux (via AcrAB-TolC) to the extracellular space. AcrB is the pump spanning the cytoplasmic membrane, TolC is an unspecific outer membrane protein, and AcrA is the membrane fusion protein, which spans the periplasmic space and thereby connects the pores formed by AcrB and TolC. A local repressor AcrR controls the expression of the acrAB genes in the absence of MarA (84), (97).
Some less hydrophilic quinolones like nalidixic acid are assumed to partially diffuse directly through the lipid bilayer of the outer membrane (71). However, diffusion of small $\left(M_{\mathrm{r}}<\right.$ 700) hydrophilic molecules, usually nutrients, occurs through porins, channel-forming proteins in the outer membrane. One of the best studied porins is the trimeric OmpF porin of E. coli, which is the major entry site for fluoroquinolones (72). Beside various environmental factors, e.g., osmolarity, temperature, $\mathrm{pH}$, which can modulate the expression of OmpF (73), mutations abolishing the function and/or the expression of OmpF have been shown to result in reduced susceptibility to fluoroquinolones and unrelated drugs (74), (75). Compared to a gyrA mutation the loss of OmpF porin function has less impact on the quinolone resistance (76).

Increased drug export has been identified as a widely distributed mechanism of broad-spectrum resistance to antibiotics. One of the best-studied systems of antibiotic export is that controlled by the mar-operon of E.coli (77) which negatively controls the expression of $\mathrm{OmpF}$ and positively controls the expression of the efflux pump AcrAB-TolC (Fig. 7). This pump belongs to the RND efflux systems, one of four known major classes of transport systems. Several homologous efflux pumps involved in quinolone resistance have been identified in Gram-negative enterobacteria (78), Neisseria gonorrhoeae (79), and P.aeruginosa (80), (81), (82), (83). While efflux pumps significantly contribute to the natural multiple-drug resistance of and have a high impact on fluoroquinolone resistance in $P$. aeruginosa, their role for quinolone resistance in other Gram-negatives is less well established (84). Increased efflux is found in clinical isolates as well as in laboratory mutants, but is associated with a much lesser increase in resistance compared to target-mediated mutations (85). The genetic basis for increased efflux is poorly understood and in E. coli mutations affecting the global regulatory component MarR or local repressors, like AcrR can be involved (Fig. 7) (86).

In Gram-positives drug efflux pumps belonging to the major facilitator family (87) have also been identified as factors modulating the fluoroquinolone resistance. These include NorA of S. aureus (88), (89) and PmrA of S. pneumoniae (90), which can be inhibited by reserpine and predominantly affect the activities of hydrophilic compounds, like norfloxacin and ciprofloxacin, but not those of more hydrophobic derivatives, like sparfloxacin or moxifloxacin (91).

\section{Outlook}

Within 15 years the fluoroquinolone class of antibacterial agents has become one of the most important drug classes showing high bactericidal activity against a broad range of Gram-positive and Gram-negative pathogens. Combined with favorable pharmacokinetics the pharmacodynamic features of the fluoroquinolones made these drugs most powerful chemotherapeutic agents for nearly all kinds of infections. However, clinically relevant resistance has developed even in strains belonging to highly susceptible species, most probably due to a high selective pressure by inappropriate use of these drugs. Thus, strictly regulated indications for use are necessary to avoid rapid development of resistance and to conserve this potential for the future. While the synthetic quinolone antimicrobial drugs are advantageous over naturally occurring by lack of both enzymatic inactivation mechanism and 
transferable resistance it would be naive thinking that development of resistance is impossible. A promising way of saving the antimicrobial potential of new drugs is their prudent use for strictly defined indications and a continuing monitoring of resistance development.

\section{References}

${ }^{1}$ Rosamond J, Allsop A. Harnessing the power of the genome in the search for new antibiotics. Science 2000; 287: 1973-6

${ }^{2}$ Wang JC. DNA topoisomerases. Annu. Rev. Biochem. 1996; 65: 635-92

${ }^{3}$ Wang JC. Interaction between DNA and an Escherichia coli protein omega. J. Mol. Biol. 1971; 55: 523-33

${ }^{4}$ Gellert M, Mizuuchi K, O'Dea MH, Nash HA. DNA gyrase: an enzyme that introduces superhelical turns into DNA. Proc. Natl. Acad. Sci. U.S.A. 1976; 73: 3872-6

${ }^{5}$ Maxwell A. DNA gyrase as a drug target. Trends. Microbiol. 1997; 5: $102-9$

${ }^{6}$ Reece RJ, Maxwell A. DNA gyrase: structure and function. Crit. Rev. Biochem. Mol. Biol. 1991; 26: 335-75

${ }^{7}$ Berger JM, Gamblin SJ, Harrison SC, Wang JC. Structure and mechanism of DNA topoisomerase II. Nature 1996; 379: 22532

${ }^{8}$ Kato J-I, Nishimura Y, Imamura Y, Niki H, Hiraga S, Suzuki H. New topoisomerase essential for chromosome segregation in E. coli. Cell 1990; 63: $393-404$

${ }^{9}$ Adams DE, Shekhtman EM, Zechiedrich EL, Schmid MB, Cozzarelli NR. The role of topoisomerase IV in partitioning bacterial replicons and the structure of catenated intermediates in DNA replication. Cell 1992; 71: 277-88

${ }^{10}$ Vizan JL, Hernandez-Chico C, del Castillo I, Moreno F. The peptide antibiotic microcin B17 induces double-strand cleavage of DNA mediated by E. coli DNA gyrase. EMBO J 1991; 10: 467-76

11 Oram M, Dosanjh B, Gormley NA, Smith CV, Fisher LM, Maxwell A, Duncan K. Mode of action of GR122222X, a novel inhibitor of bacterial DNA gyrase. Antimicrob. Agents Chemother. 1996; 40: $473-6$

12 Osburne MS, Maiese WM, Greenstein M. In vitro inhibition of bacterial DNA gyrase by cinodine, a glycocinnamoylspermidine antibiotic. Antimicrob. Agents Chemother. 1990; 34: 1450-2

13 Osburne MS. Characterization of a cinodine-resistant mutant of Escherichia coli. J Antibiot. (Tokyo.) 1995; 48: 1359-61

${ }^{14}$ Nakada N, Shimada H, Hirata T, Aoki Y, Kamiyama T, Watanabe J, Arisawa M. Biological characterization of cyclothialidine, a new DNA gyrase inhibitor. Antimicrob. Agents Chemother. 1993; 37: 2656-61

${ }^{15}$ Yamaji K, Masubuchi M, Kawahara F, Nakamura Y, Nishio A, Matsukuma S, Fujimori M, Nakada N, Watanabe J, Kamiyama T. Cyclothialidine analogs, novel DNA gyrase inhibitors. J Antibiot. (Tokyo.) 1997; 50: 402-11

${ }^{16}$ Bernard FX, Sable S, Cameron B, Provost J, Desnottes JF, Crouzet J, Blanche F. Glycosylated flavones as selective inhibitors of topoisomerase IV. Antimicrob. Agents Chemother. 1997; 41: 992-8

${ }^{17}$ Maxwell A. The interaction between coumarin drugs and DNA gyrase. Mol. Microbiol. 1993; 9: 681-6

18 Gellert M, O'Dea MH, Itoh T, Tomizawa J. Novobiocin and coumermycin inhibit DNA supercoiling catalyzed by DNA gyrase. Proc. Natl. Acad. Sci. U.S.A. 1976; 73: 4474-8

${ }^{19}$ Sugino A, Higgins NP, Brown PO, Peebles CL, Cozzarelli NR. Energy coupling in DNA gyrase and the mechanism of action of novobiocin. Proc. Natl. Acad. Sci. U.S.A. 1978; 75: 4838-42

${ }^{20}$ Hooper DC, Wolfson JS, McHugh GL, Winters MB, Swartz MN. Effects of novobiocin, coumermycin A1, clorobiocin, and their analogs on Escherichia coli DNA gyrase and bacterial growth. Antimicrob. Agents Chemother. 1982; 22: 662-71
${ }^{21}$ Lesher GY, Froelich EJ, Gruett MD, Bailey JH, Brundage RP. 1,8Naphthyridine derivatives, a new class of chemotherapy agents. J. Med. Chem. 1962; 5: $1063-5$

22 Koga H, Itoh A, Murayama S, Suzue S, Irikura T. Structure-activity relationships of antibacterial 6,7- and 7,8-disubstituted 1-alkyl-1,4-dihydro-4-oxoquinoline-3-carboxylic acids. J Med. Chem. 1980; 23: 1358-63

${ }^{23}$ Eliopoulos GM, Eliopoulos CT. Quinolone Antimicrobial Agents, Activity in vitro of the quinolones. In: Hooper DC, Wolfson JS, editors. Washington DC: American Society for Microbiology, 1993: $161-93$

${ }^{24}$ Naber KG, Adam D. Expertengruppe der Paul-Ehrlich-Gesellschaft. Einteilung der Fluorchinolone. Chemotherapie Journal 1998; 7: 66-8

${ }^{25}$ Bauernfeind A. Comparison of the antibacterial activities of the quinolones Bay 12-8039, gatifloxacin (AM 1155), trovafloxacin, clinafloxacin, levofloxacin and ciprofloxacin. J Antimicrob. Chemother. 1997; 40: 639-51

${ }^{26}$ Drlica K, Xu C, Wang JY, Burger RM, Malik M. Fluoroquinolone action in mycobacteria: similarity with effects in Escherichia coli and detection by cell lysate viscosity. Antimicrob. Agents Chemother. 1996; 40: 1594-9

${ }^{27}$ Ednie LM, Jacobs MR, Appelbaum PC. Comparative activities of clinafloxacin against Gram-positive and -negative bacteria. Antimicrob. Agents Chemother. 1998; 42: 1269-73

${ }^{28}$ Felmingham D, Robbins MJ, Ingley K, Mathias I, Bhogal H, Leakey A, Ridgway GL, Gruneberg RN. In-vitro activity of trovafloxacin, a new fluoroquinolone, against recent clinical isolates. J Antimicrob. Chemother. 1997; 39 Suppl B: $43-9$

${ }^{29}$ Thornsberry C. Quinolone antibacterials, The in vitro antibacterial activity of quinolones: a review. In: Kuhlmann J, Dalhoff A, Zeiler H-J, editors. Handbook of Experimental Pharmacology. Berlin: Springer Verlag, 1998: 167-78

${ }^{30}$ Zhao X, Wang JY, Xu C, Dong Y, Zhou J, Domagala J, Drlica K Killing of Staphylococcus aureus by C-8-methoxy fluoroquinolones. Antimicrob. Agents Chemother. 1998; 42: 956-8

${ }^{31}$ Rastogi N, Labrousse V, Goh KS, De Sousa JP. Antimycobacterial spectrum of sparfloxacin and its activities alone and in association with other drugs against Mycobacterium avium complex growing extracellularly and intracellularly in murine and human macrophages. Antimicrob. Agents Chemother. 1991; 35: 247380

32 Saito $\mathrm{H}$, Tomioka $\mathrm{H}$, Sato $\mathrm{K}$, Dekio $\mathrm{S}$. In vitro and in vivo antimycobacterial activities of a new quinolone, DU-6859a. Antimicrob. Agents Chemother. 1994; 38: 2877-82

${ }^{33}$ Yew WW, Piddock LJ, Li MS, Lyon D, Chan CY, Cheng AF. In-vitro activity of quinolones and macrolides against mycobacteria. J Antimicrob. Chemother. 1994; 34: 343-51

${ }^{34}$ Blondeau JM. A review of the comparative in-vitro activities of 12 antimicrobial agents, with a focus on five new respiratory quinolones'. J Antimicrob. Chemother. 1999; 43 Suppl B: 1-11

35 Goss WA, Deitz WH, Cook TM. Mechanism of action of nalidixic acid on Escherichia coli (I). J Bacteriol 1964; 88: 1112-8

${ }^{36}$ Goss WA, Deitz WH, Cook TM. Mechanism of action of nalidixic acid on Escherichia coli (II). J Bacteriol 1965; 89: 1068-74

${ }^{37}$ Gellert M, Mizuuchi K, O'Dea MH, Itoh T, Tomizawa JI. Nalidixic acid resistance: a second genetic character involved in DNA gyrase activity. Proc. Natl. Acad. Sci. U.S.A. 1977; 74: 4772-6

${ }^{38}$ Phillips I, Culebras E, Moreno F, Baquero F. Induction of the SOS response by new 4-quinolones. J Antimicrob. Chemother. 1987; 20: $631-8$

${ }^{39}$ Little JW, Mount DW. The SOS regulatory system of Escherichia coli. Cell 1982; 29: 11-22

${ }^{40}$ Bourguignon GJ, Levitt M, Sternglanz R. Studies on the mechanism of action of nalidixic acid. Antimicrob. Agents Chemother. 1973; 4 : $379-86$ 
${ }^{41}$ Martens R, Wetzstein HG, Zadrazil F, Capelari M, Hoffmann P, Schmeer N. Degradation of the fluoroquinolone enrofloxacin by wood-rotting fungi. Appl. Environ. Microbiol. 1996; 62: 4206-9

42 Hooper DC, Wolfson JS. Bacterial resistance to the quinolone antimicrobial agents. Am. J. Med. 1989; 87: 17S-23S

${ }^{43}$ Kresken M, Hafner D. Prävalenz der Antibiotikaresistenz bei klinisch wichtigen Infeketionserregern in Mitteleuropa. Chemotherapie Journal 1996; 5: 225-30

${ }^{44}$ Heisig P. Genetic evidence for a role of parC mutations in development of high-level fluoroquinolone resistance in Escherichia coli. Antimicrob. Agents Chemother. 1996; 40: 879-85

${ }^{45}$ Lehn N, Stower-Hoffmann J, Kott T, Strassner C, Wagner H, Kronke M, Schneider-Brachert W. Characterization of clinical isolates of Escherichia coli showing high levels of fluoroquinolone resistance. J. Clin. Microbiol. 1996; 34: 597-602

${ }^{46}$ Everett MJ, Jin YF, Ricci V, Piddock LJ. Contributions of individual mechanisms to fluoroquinolone resistance in 36 Escherichia coli strains isolated from humans and animals. Antimicrob. Agents Chemother. 1996; 40: 2380-6

${ }^{47}$ Conrad S, Oethinger M, Kaifel K, Klotz G, Marre R, Kern WV. gyrA mutations in high-level fluoroquinolone-resistant clinical isolates of Escherichia coli. J Antimicrob. Chemother. 1996; 38: 443-55

${ }^{48}$ Heisig P, Tschorny R. Characterization of fluoroquinolone-resistant mutants of Escherichia coli selected in vitro. Antimicrob. Agents Chemother. 1994; 38: 1284-91

${ }^{49}$ Hane MW, Wood TH. Escherichia coli K-12 mutants resistant to nalidixic acid: genetic mapping and dominance studies. J. Bacteriol. 1969; 99: 238-41

${ }^{50}$ Nakamura S, Nakamura M, Kojima T, Yoshida H. gyrA and gyrB mutations in quinolone-resistant strains of Escherichia coli. Antimicrob. Agents Chemother. 1989; 33: $254-5$

${ }^{51}$ Heisig P, Wiedemann B. Use of a broad-host-rage gyrA plasmid for genetic characterization of fluoroquinolone-resistant gramnegative bacteria. Antimicrob. Agents Chemother. 1991; 35: 2031-6

52 Cohen SP, McMurry LM, Hooper DC, Wolfson JS, Levy SB. Crossresistance to fluoroquinolones in multiple-antibiotic-resistant (Mar) Escherichia coli selected by tetracycline or chloramphenicol: decreased drug accumulation associated with membrane changes in addition to $\mathrm{OmpF}$ reduction. Antimicrob. Agents Chemother. 1989; 33: $1318-25$

${ }^{53}$ Heisig P. Antibiotic Resistance - Recent Development and Future Perspectives, Mechanisms and Epidemiology of Fluoroquinolone Resistance in Enterobacteriaceae. In: Hakenbeck R, editor. Biospektrum Special Edition. Heidelberg: Spektrum, 1997: 42-6

54 Yoshida H, Bogaki M, Nakamura M, Nakamura S. Quinolone resistance determining region in the DNA gyrase gyrA gene of Escherichia coli. Antimicrob. Agents Chemother. 1990; 34: 1271-2

${ }^{55}$ Heisig P, Schedletzky H, Falkenstein-Paul H. Mutations in the gy$r A$ gene of a highly fluoroquinolone-resistant clinical isolate of Escherichia coli. Antimicrob. Agents Chemother. 1993; 37: 696701

${ }^{56}$ Hoshino K, Kitamura A, Morrissey I, Sato K, Kato J, Ikeda H. Comparison of inhibition of Escherichia coli topoisomerase IV by quinolones with DNA gyrase inhibition. Antimicrob. Agents Chemother. 1994; 38: 2623-7

${ }^{57}$ Khodursky AB, Zechiedrich EL, Cozzarelli NR. Topoisomerase IV is a target of quinolones in Escherichia coli. Proc. Natl. Acad. Sci. U.S.A. 1995; 92: $11801-5$

${ }^{58}$ Vila J, Ruiz J, Goni P, De Anta MT. Detection of mutations in ParC in quinolone-resistant clinical isolates of Escherichia coli. Antimicrob. Agents Chemother. 1996; 40: 491-3

${ }^{59}$ Kumagai Y, Kato JI, Hoshino K, Akasaka T, Sato K, Ikeda H. Quinolone-resistant mutants of Escherichia coli DNA topoisomerase IV ParC gene. Antimicrob. Agents Chemother. 1996; 40: 710-4
${ }^{60}$ Belland RJ, Morrison SG, Ison C, Huang WM. Neisseria gonorrhoeae acquires mutations in analogous regions of gyrA and parC in fluoroquinolone-resistant isolates. Mol. Microbiol. 1994; 14: $371-80$

${ }^{61}$ Holzgrabe U, Heisig P. New 4-quinolone derivatives in review. Pharm. Unserer. Zeit. 1999; 28: 30-5

62 Ferrero L, Cameron B, Crouzet J. Analysis of gyrA and grlA mutations in stepwise-selected ciprofloxacin-resistant mutants of Staphylococcus aureus. Antimicrob. Agents Chemother. 1995; 39 : $1554-8$

${ }^{63}$ Domagala JM. Structure-activity and structure-side-effect relationships for the quinolone antibacterials. J Antimicrob. Chemother. 1994; 33: 685-706

64 el Amin NA, Jalal S, Wretlind B. Alterations in GyrA and ParC associated with fluoroquinolone resistance in Enterococcus faecium. Antimicrob. Agents Chemother. 1999; 43: $947-9$

${ }^{65}$ Kanematsu E, Deguchi T, Yasuda M, Kawamura T, Nishino Y, Kawada Y. Alterations in the GyrA subunit of DNA gyrase and the ParC subunit of DNA topoisomerase IV associated with quinolone resistance in Enterococcus faecalis. Antimcirob. Agents Chemother. 1998; 42: 433-5

${ }^{66}$ Pan XS, Fisher LM. Cloning and characterization of the parC and parE genes of Streptococcus pneumoniae encoding DNA topoisomerase IV: role in fluoroquinolone resistance. J. Bacteriol. 1996; 178: 4060-9

${ }^{67}$ Pan XS, Fisher LM. Targeting of DNA gyrase in Streptococcus pneumoniae by sparfloxacin: selective targeting of gyrase or topoisomerase IV by quinolones. Antimicrob. Agents Chemother. 1997; 41: $471-4$

${ }^{68}$ Kotera Y, Watanabe M, Yoshida S, Inoue M, Mitsuhashi S. Factors influencing the uptake of norfloxacin by Escherichia coli. J Antimicrob. Chemother. 1991; 27: 733-9

${ }^{69}$ Nikaido H, Thanassi DG. Penetration of lipophilic agents with multiple protonation sites into bacterial cells: tetracyclines and fluoroquinolones as examples. Antimicrob. Agents Chemother. 1993; 37: $1393-9$

${ }^{70}$ Nikaido H. Antibiotic resistance caused by Gram-negative mutlidrug efflux pumps. Clin. Infect. Dis. 1998; 27 Suppl 1: S32-541

${ }^{71}$ Chapman JS, Georgopapadakou NH. Routes of quinolone permeation in Escherichia coli. Antimicrob. Agents Chemother. 1988; 32: 438-42

72 Sawai T, Yamaguchi A, Saiki A, Hoshino K. OmpF channel permeability of quinolones and their comparison with beta-lactams. FEMS Microbiol. Lett. 1992; 74: 105-8

${ }^{73}$ Pratt LA, Hsing W, Gibson KE, Silhavy TJ. From acids to osmZ: multiple factors influence synthesis of the OmpF and OmpC porins in Escherichia coli. Mol. Microbiol. 1996; 20: $911-7$

${ }^{74}$ Gutmann L, Williamson R, Moreau N, Kitzis MD, Collatz E, Acar JF, Goldstein FW. Cross-resistance to nalidixic acid, trimethoprim, and chloramphenicol associated with alterations in outer membrane proteins of Klebsiella, Enterobacter, and Serratia. J. Infect. Dis. 1985; 151: $501-7$

${ }^{75}$ Nikaido H. Prevention of drug access to bacterial targets: permeability barriers and active efflux. Science 1994; 264: $382-8$

${ }^{76}$ Chapman JS, Bertasso A, Georgopapadakou NH. Fleroxacin resistance in Escherichia coli. Antimicrob. Agents Chemother. 1989; 33: 239-41

${ }^{77}$ Cohen SP, Hooper DC, Wolfson JS, Souza KS, McMurry LM, Levy SB. Endogenous active efflux of norfloxacin in susceptible Escherichia coli. Antimicrob. Agents Chemother. 1988; 32: 1187-91

${ }^{78}$ Ishii H, Sato K, Hoshino K, Sato M, Yamaguchi A, Sawai T, Osada Y. Active efflux of ofloxacin by a highly quinolone-resistant strain of Proteus vulgaris. J Antimicrob. Chemother. 1991; 28: 827-36

${ }^{79}$ Hagman KE, Pan W, Spratt B, Balthazar JT, Judd RC, Shafer WM. Resistance of Neisseria gonorrhoeae to antimicrobial hydrophobic agents is modulated by the mtrRCDE efflux system. Microbiology 1995; 141: $611-22$ 
${ }^{80} \mathrm{Li} \mathrm{XZ}$, Nikaido H, Poole K. Role of mexA-mexB-oprM in antibiotic efflux in Pseudomonas aeruginosa. Antimicrob. Agents Chemother. 1995; 39: $1948-53$

81 Poole K, Gotoh N, Tsujimoto H, Zhao Q, Wada A, Yamasaki T, Neshat $\mathrm{S}$, Yamagishi J, Li XZ, Nishino T. Overexpression of the mexC-mexD-oprJ efflux operon in $n f x B$-type multidrug-resistant strains of Pseudomonas aeruginosa. Mol. Microbiol. 1996; 21: $713-24$

${ }^{82}$ Fukuda H, Hosaka M, Hirai K, lyobe S. New norfloxacin resistance gene in Pseudomonas aeruginosa PAO. Antimicrob. Agents Chemother. 1990; 34: 1757-61

${ }^{83}$ Yoneyama $\mathrm{H}$, Ocaktan A, Tsuda M, Nakae T. The role of mexgene products in antibiotic extrusion in Pseudomonas aeruginosa. Biochem. Biophys. Res. Commun. 1997; 233: $611-8$

${ }^{84}$ Ma D, Cook DN, Hearst JE, Nikaido H. Efflux pumps and drug resistance in Gram-negative bacteria. Trends. Microbiol. 1994; 2: 489-93

${ }^{85}$ Kern WV, Oethinger M, Jellen-Ritter AS, Levy SB. Non-target gene mutations in the development of fluoroquinolone resistance in Escherichia coli. Antimicrob. Agents Chemother. 2000; 44: $814-20$

${ }^{86}$ Alekshun MN, Levy SB. Regulation of chromosomally mediated multiple antibiotic resistance: the mar regulon. Antimicrob. Agents Chemother. 1997; 41: 2067-75

${ }^{87}$ Paulsen IT, Brown MH, Skurray RA. Proton-dependent multidrug efflux systems. Microbiol. Rev. 1996; 60: 575-608

${ }^{88}$ Yoshida H, Bogaki M, Nakamura S, Ubukata K, Konno M. Nucleotide sequence and characterization of the Staphylococcus aureus norA gene, which confers resistance to quinolones. J Bacteriol 1990; 172: $6942-9$

${ }^{89}$ Neyfakh AA, Borsch CM, Kaatz GW. Fluoroquinolone resistance protein NorA of Staphylococcus aureus is a multidrug efflux transporter. Antimicrob. Agents Chemother. 1993; 37: 128 -9

${ }^{90}$ Brenwald NP, Gill MJ, Wise R. Prevalence of a putative efflux mechanism among fluoroquinolone-resistant clinical isolates of Streptococcus pneumoniae. Antimicrob. Agents Chemother. 1998; 42: $2032-5$

${ }^{91}$ Gill MJ, Brenwald NP, Wise R. Identification of an efflux pump gene, $p m r A$, associated with fluoroquinolone resistance in Streptococcus pneumoniae. Antimicrob. Agents Chemother. 1999; 43: $187-9$

${ }^{92}$ Akasaka T, Onodera Y, Tanaka M, Sato K. Cloning, expression, and enzymatic characterization of Pseudomonas aeruginosa topoisomerase IV. Antimicrob. Agents Chemother. 1999; 43: 530-6

${ }^{93}$ Kureishi A, Diver JM, Beckthold B, Schollaardt T, Bryan LE. Cloning and nucleotide sequence of Pseudomonas aeruginosa DNA gyrase gyrA gene from strain PAO1 and quinolone-resistant clinical isolates. Antimicrob. Agents Chemother. 1994; 38: 1944-52

${ }^{94}$ Vila J, Ruiz J, Goni P, Jimenez DA. Quinolone-resistance mutations in the topoisomerase IV parC gene of Acinetobacter baumannii. J Antimicrob. Chemother. 1997; 39: 757-62

${ }^{95}$ Cohen SP, Hachler H, Levy SB. Genetic and functional analysis of the multiple antibiotic resistance (mar) locus in Escherichia coli. J Bacteriol 1993; 175: 1484-92

${ }^{96}$ Ma D, Cook DN, Alberti M, Pon NG, Nikaido H, Hearst JE. Genes acrA and $a c r B$ encode a stress-induced efflux system of Escherichia coli. Mol. Microbiol. 1995; 16: 45-55

${ }^{97}$ Ma D, Alberti M, Lynch C, Nikaido H, Hearst JE. The local repressor AcrR plays a modulating role in the regulation of $a c r A B$ genes of Escherichia coli by global stress signals. Mol. Microbiol. 1996; 19: $101-12$

\section{Prof. Dr. Peter Heisig}

Pharmazeutische Biologie Universität Hamburg Bundesstraße 45

20146 Hamburg

Germany

E-mail: heisig@chemie.uni-hamburg.de

Fax: +49 (0)40-42838-3895

Phone: +49 (0)40-42838-3899 